\title{
T4d Stage Finding
}

National Cancer Institute

\section{Source}

National Cancer Institute. T4d Stage Finding. NCI Thesaurus. Code C48736.

A general term that refers to a TNM finding of a primary tumor with direct invasion of adjacent structures. The definition of T4d TNM finding depends on the specific type of cancer that it refers to; for example, for breast cancer it refers to a primary tumor that meets the clinical-pathologic criteria of inflammatory carcinoma; for ocular adnexal lymphoma it refers to a primary tumor with intracranial spread; for carcinoma of the conjunctiva it refers to a primary tumor that invades the brain. 